\title{
Toxicity of Phase I Radiation Oncology Trials: Worldwide Experience
}

\author{
C. Glass \\ Jefferson Medical College
}

R. B. Den

Thomas Jefferson University and Hospitals

\section{A. P. Dicker}

Thomas Jefferson University and Hospitals

Y. R. Lawrence

Thomas Jefferson University and Hospitals

\section{Follow this and additional works at: https://jdc.jefferson.edu/bodinejournal \\ Part of the Oncology Commons \\ Let us know how access to this document benefits you}

\section{Recommended Citation}

Glass, C.; Den, R. B.; Dicker, A. P.; and Lawrence, Y. R. (2010) "Toxicity of Phase I Radiation Oncology Trials: Worldwide Experience," Bodine Journal: Vol. 3 : Iss. 1 , Article 31.

DOI: https://doi.org/10.29046/TBJ.003.1.030

Available at: https://jdc.jefferson.edu/bodinejournal/vol3/iss1/31

This Article is brought to you for free and open access by the Jefferson Digital Commons. The Jefferson Digital Commons is a service of Thomas Jefferson University's Center for Teaching and Learning (CTL). The Commons is a showcase for Jefferson books and journals, peer-reviewed scholarly publications, unique historical collections from the University archives, and teaching tools. The Jefferson Digital Commons allows researchers and interested readers anywhere in the world to learn about and keep up to date with Jefferson scholarship. This article has been accepted for inclusion in Bodine Journal by an authorized administrator of the Jefferson Digital Commons. For more information, please contact: JeffersonDigitalCommons@jefferson.edu. 


\section{Toxicity of Phase I Radiation Oncology Trials: Worldwide Experience}

Glass, C., ${ }^{1}$ Den, R.B., ${ }^{2}$ Dicker, A.P., ${ }^{2}$ Lawrence, Y.R. $^{2}$

${ }^{1}$ Jefferson Medical College, Philadelphia, PA,

'Department of Radiation Oncology, Thomas Jefferson University and Hospitals, Philadelphia, PA

\section{Introduction}

Informed consent involves understanding the risks and benefits of trial enrollment. This is challenging in the phase I setting since true quantitative information is never known. We therefore performed an analysis of published radiation oncology (RO) phase I trials emphasizing patient outcomes. To our knowledge, no such systemic analysis has previously been published.

\section{Methods}

All phase I and I/II RO clinical trials published in the years 2001, 2005 and 2009 were identified via a PubMed search. All trials utilized radiation therapy, and many also included cytotoxic and/or biologic agents. Articles only published in abstract form were excluded, as were strict phase II trials, non-English studies, and non-cancer pathologies. Variables extracted from the full-text of manuscripts included demographics, treatment site, trial design, toxicity, ethical and legal considerations, and response rate. In the event of multiple adverse events in a single subject, these were calculated as per-study, not per-subject.

\section{Results}

A total of 119 trials were identified, 17 trials were excluded since the manuscript was unobtainable, leaving 102 trials for review (2001, 27 ; 2005, 45; and 2009, 30). Of these trials, 59\% were performed in the USA and $66 \%$ were multi-institutional. Sixty-eight percent (68\%) of trials were phase 1 and $32 \%$ were phase I/II trials. The most frequent treatment sites were lung $22 \%$, brain $12 \%$, rectal $11 \%$, and head-and-neck $11 \%$. Seventy-one trials involved doseescalating a chemotherapeutic or biologic agent, 21 trials doseescalated radiation alone, 2 trials escalated both radiation and/or a chemotherapeutic agent, and 8 trials involved no dose-escalation. All but 18 trials used a traditional / modified Fibonacci design. A total of 4553 subjects were enrolled; $65 \%$ were male, with a mean age of 62. Median or mean follow-up was 25.2 months. There were a total of 39 treatment related deaths, and 1881 major toxicities (defined as grade 3 or worse excluding death according to CTCAE criteria or equivalent) corresponding to an average risk of $0.1 \%$ and $41 \%$ per patient, respectively. The reporting of benefit was inconsistent and highly variable preventing meaningful analysis.

\section{Conclusion}

Approximately 1500 patients are enrolled per year in radiation oncology phase I trials, the majority in the USA. Although the risk of death is low $(<1 \%)$, the risk of major toxicity is significant $(>40 \%)$. These figures have to be considered in the context of expected benefit/toxicity of standard of care RO treatment. Although we were able to quantify risk, we were unable to quantify benefit. Although preliminary, this data sheds light on the risks of patient participation in phase I RO trials. 